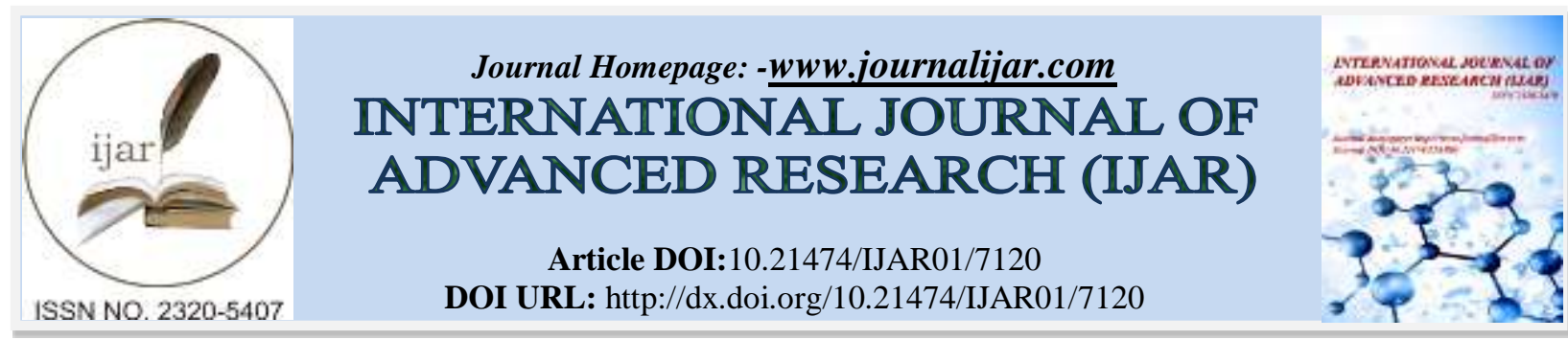

RESEARCH ARTICLE

\title{
ANTI-IMMIGRANT RHETORIC, SHIFTING IDEOLOGIES AND THE CRIMINALISATION OF THE 'OTHER': AN ANALYSIS OF MIGRANT CRIME AND THREAT DISCOURSE IN THE NORWEGIAN PRINT MEDIA FROM 2000 TO 2014
}

\author{
Natalie Nilsen. \\ BCCJ BSocSci (Psych) MCCJ (Hons).
}

\section{Manuscript Info}

Manuscript History

Received: 16 March 2018

Final Accepted: 18 April 2018

Published: May 2018

Keywords:

race-threat theory; agenda-setting hypothesis; crime and the media; crime and immigration; the Norwegian media; thematic analyses.

\begin{abstract}
This paper examines the construction of "immigrants" and "threat" in violent crime media coverage in Norway, by drawing upon themes from McCombs and Shaw's (1972) agenda-setting hypothesis, and Blalock's (1967) race-threat theory. Results from the thematic qualitative analysis and the themes identified suggest an escalating antiimmigrant rhetoric in Norway's media, with an agenda that demonises deviant 'others' (i.e. immigrants, particularly of the 'non-Western' variety). The current study is limited to print media, however, future research in this field should examine other media mediums, including visual media and social media, as well as comparing and exploring the themes of this paper within other national contexts.
\end{abstract}

Copy Right, IJAR, 2018. All rights reserved.

\section{Introduction}

At approximately 3:25pm on 22 July 2011, Norway was struck with two consecutive lone-wolf terrorist attacks. The first attack was a car bomb explosion that went off in the executive government quarter in the heart of Norway's capital, Oslo, which killed 8 people and injured 209, 12 of them seriously. The second attack occurred less than two hours later at the AUF-run summer camp, on the island of Utøya, located in the neighbouring county of Buskerud. A gunman, dressed in a homemade police uniform and displaying false identification papers gained access to the island and subsequently opened fire on young AUF-party members, killing 69 and injuring 110, 55 of them critically. The youngest shooting victim on Utøya was only 14 years old. Taken together, these were the deadliest incidents of violence to occur on Norwegian soil since World War II.

The siege on Utøya lasted well over an hour, with police delays in obtaining boats, hampering efforts to apprehend the assailant, whose identity was initially concealed from the media, and hence, the public. Without any proof, numerous news outlets and commentators in both Norway and abroad began to openly blame the attacks in Norway on Islamic militants. There were several incidents during the events of the 22 nd of July of mob violence, with Muslims (or anyone identified as Muslim or Middle Eastern in appearance) being pulled out of buses, as well as being spat on and beaten (Eriksen, 2013). The perpetrator, however, was not an Islamic militant, nor an immigrant; in fact, the culprit was a 32-year-old ethnic Norwegian and far-right extremist by the name of Anders Behring Breivik. In the aftermath of these incidents, there was considerable Internet activity in online newspaper debate forums in support of Breivik, with the posting of numerous xenophobic comments, especially in relation to nonwestern immigrants (Ladegaard, 2013). More recently, an opinion poll in early 2012 indicated that 25 percent of the population believed that there were too many Muslims in the country (Eriksen, 2013). The news coverage of the 
events that took place on the 22nd of July, 2011 initially blamed non-Norwegian terrorist organisations for this incident of extreme violence, at a time of increased politicisation regarding immigration, especially of nonEuropeans, into Western Europe in general, and Norway in particular. (Esses et al. 2013; Markert 2010; Chamlin 2009; Bosworth et al. 2008; Hudson 2008; Hogg 2007; Altheide 2002). The coverage of the above event illustrates how non-Norwegians were initially blamed for an incident involving extreme violence, at a time of increased politicisation regarding immigration, especially of non-Europeans, into Western Europe in general, and Norway in particular.

\section{Media representations and public opinion}

Political and media discourses associating Muslim immigrants to criminal threat have emerged strongly in the $21 \mathrm{st}$ century (Bakken, 1998; Lithman, 2004; Rydgren, 2008; Bangstad, 2015). Previously, assumptions that Muslims have strong ties to family, community and religion have served to explain their lower crime rates when compared to those of white and other minority ethnic groups (Hudson \& Bramhall, 2005). In contrast, currently, the very same constructions are now being drawn to explain Muslim criminality, particularly around terrorism, and to a certain extent in Norway at least, other violent crimes, such as rape (Hudson, 2008, Wiggen, 2012). One way of understanding the growth of a discourse linking Muslim immigrants to criminal threat is Blalock's (1967) group threat theory. According to Blalock, when minority groups threaten the culture or economic well-being of the ethnic majority group by growing in number, this elicits anti-immigrant attitudes amongst members of the majority group. These representations of "threat" shape public opinion, and in turn, the acceptance or rejection of immigrant groups (Esses et al., 2013). A considerable body of work conducted by various researchers has shown that media representations have consequences for public attitudes toward immigrants (e.g., Fleras \& Kunz, 2001; Chricos \& Escholz, 2002; Nafstad et al., 2009; Phelps et al., 2011; Jewkes, 2011; Berg \& Gleditsch, 2014; Bangstad, 2015).

\section{Current study}

Despite emerging work on the media construction of terrorism, there has been limited research on changing media representations of immigrants and criminal threat, given the larger political global concerns around terrorism, especially outside English-speaking nations. For this reason, Norway provides a unique canvas for such a study. This is primarily because Norway's public image is one of tolerance and equality, which is chiefly evident through their implementation of the Nordic Welfare Model, whose ideals they share with other Scandinavian countries such as Denmark and Sweden. However, unlike Denmark and Sweden, Norway is not a member of the European Union, in part because of its interrelated nationalistic tendencies and Euroscepticism. (Lithman, 2004; Wiggen, 2012; Kymlicka, 2012). The violent crime category, however, has the most potential to be damaging to Norway's social fabric (Gullestad, 2002). Using a random sample of violent crime reports (stratified by three time-periods), the current study examines three key research questions, which will be expanded upon in the conceptual background section.

Implementing both a quantitative and qualitative thematic content analysis, this study relies on the crime content of the two most prominent Norwegian-language newspapers currently in circulation in Norway, Aftenposten (AP) and Verdens Gang (VG) (with a respective readership of 412,005 and 380,190 individuals daily (Press Reference, 2015). Furthermore, even though the total circulation of newspapers fell 2.8 percent in 2009 , the average Norwegian still reads 1.8 newspapers per day (The Nordic Page, 2009; Slaata, 2015).

\section{Conceptual Background and Review of Prior Research: Group Threat Theory and Agenda-Setting in the Media within a Norwegian Context}

The conceptual framework for this paper includes group threat theory, agenda-setting and social construction arguments to understand how the media contributes to the idea of particular groups being viewed as hostile. In addition, this section will also include the key findings of relevant prior research on the representation of immigrants and crime in both Norway and abroad. For this study, perceptions of threat will be defined from the perspective of Hubert Blalock's (1967) racial group threat theory. Group threat theory suggests that, as the percentage of the population that are considered minorities increases in number, so does the majority populations' fear of a threat to their political, economic, or personal well-being, with this greater perceived threat corresponding to an increase in prejudiced attitudes toward the minority group, or groups (Blalock, 1967).

\section{Politics, Agenda-Setting, and the Media}

Several researchers, such as Jewkes $(2004 ; 2011)$ and Maneri and ter Wal (2005) assert that the mass media can be viewed as a somewhat distorted mirror in relation to critical issues deliberated on by the general public, thus 
presenting a subjective version of reality, rather than reality itself. One of the main perspectives that comprehensively serves as an explanation for this process is known as agenda-setting theory, whose origins can be traced to the earlier works of sociologists Lippmann (1922) and Cohen (1963) but was not formally developed and analysed until U.S. researchers McCombs and Shaw (1972) published a study regarding the public's perceptions of the 1968 presidential elections. Drawing on these observations, McCombs and Shaw (1972) found evidence of agenda-setting by identifying that the salience of the news agenda is highly correlated to that of the voters' agenda. Furthermore, the impact of such agenda-setting is reinforced by the selectively-recorded sentiments of those in society who maintain hegemonic power, such as political leaders and prominent intellectuals.

\section{The Media, the Construction of Criminal Threat, and Blalock's (1967) Group Threat Theory}

Blalock's (1967) group threat theory provides a useful way of understanding the groups that are likely to be defined as threats to the majority population. There are essentially two primary approaches to the construction of particular groups being treated as a threat. The first is: individual threat doctrines, whereby anti-immigrant attitudes are a result of divergent, non-complementary attitudes that certain individuals in society may hold (Kinder \& Sanders, 1996; Meertens \& Pettigrew, 1997; Henry \& Sears, 2002). The second approach is group threat theory, which focuses on relations between groups, with subjects primarily identifying as being apprehensive about their group's status in society, regardless of whether the individual themselves, or indeed those close to them, are directly harmed or not (Bobo, 1988; Quillian, 1995; Fredrickson, 2002; Rosenstein, 2008; Chamlin, 2009; \& Kaya \& Karakoc, 2012). In the current paper, group threat models, rather than individual threat doctrines, are more applicable, as we will be focusing on how the media (a group institution) constructs crime, whilst providing a framework for understanding the development of criminal threat in minority populations toward the majority.

\section{Group Threat and the Media}

Perhaps the most newly-examined aspect of group threat theory, especially in relation to influencing perceptions and inciting hostility, is the role of the media, which has always played a pivotal part in drawing attention toward (or away from) an issue by the time and amount of space devoted to the subject, as well as the way in which a particular issue is framed. Moreover, the media has become much more pronounced in its influence in the half-century since Blalock (1967) initially examined race relations, owing in large part to the ubiquity of television, print, and online media today (Gorman \& McLean, 2003; Cummins \& Gordon, 2006; \& Markert, 2010). The media has primarily generated considerable attention from the public, politicians and other members of the hegemonic elite, such as academics, due to its rapid-fire method of delivery of 'real world' events tends to mask the slant of the story and prevents the viewer from recognising how the story was framed (Barkin, 2003; Kerbel, 1999). The first scholar to consider the impact of the media in relation to Blalock's (1967) group threat theory was Weimann (2000), who stated that reality is filtered through an ultimately partisan lens, referred to as constructed reality, and that this affects one perception of the world. Furthermore, the media is a mediating variable that affects the intensity of the public's hostility toward minority populations, regardless of their actual population size, because media attention may make the group seem larger than it is, and thus more threatening (Weimann, 2000). Weimann's (2000) model is a visual depiction of what Thomas \& Thomas (1928, p. 572) highlighted nearly a century ago: "If men define their situations as real, they are real in their consequences".

\section{Prior Research on Crime, Immigrants and the Media}

To date, a large body of research exists in most English-speaking Western nations regarding media representations of minorities, immigrants and crime. This research has been focused primarily around the disproportionate coverage of crimes allegedly involving minorities (media bias), and the media's negative depictions of immigrants and refugees. These themes have been shown to be a consistent part of the literature, beginning in the United States in the 1960s and 1970s. Some prominent examples of these themes are mentioned below. Initially focusing on investigating prejudice and discrimination within newsrooms, these studies indicated an imbalance of power between the White majority and Black and Hispanic journalists in the newsroom (Breed, 1955; Greenburg \& Mazingo, 1976; Wilson, 2002). This form of racism eschews overt expressions of racial superiority or inferiority and is characterised instead by a diffuse "anti-black affect - a general hostility toward blacks" (Entman, 1990, p.332). Furthermore, in 2001, Chavez analysed magazine covers from major American publications, such as Time and Newsweek, between the years of 1965 and 1999, and determined that a sense of threat and alarm regarding the perceived negative impact of immigration on the country had risen markedly, with a focus on immigrants as invaders and $76 \%$ of the descriptive terms of asylum-seekers being negative in nature, and having a similar focus on threat (e.g., asylum-seekers portrayed as terrorists and criminals). 


\section{Prior research on Crime and Immigration in the Norwegian Media}

Norway and the Norwegian media provide an interesting canvas and perspective for the concepts covered in this study for several reasons. As noted above, the public image presented by Norway to the rest of the world is that of tolerance and equality, especially noted through the Nordic Welfare Model that they share with the rest of Scandinavia and the other Nordic countries. However, the fact that it is wealthier than the other nations included in this model due to its oil ownership and production, coupled with both its continued scepticism and non-membership in the European Union and its relatively small population and research base around the current paper's topic, makes it a unique alternative for investigating representations of immigrants and crime in the media. As with other countries participating in the Nordic Welfare Model, the Norwegian media is often criticised as being biased towards the political left. However, despite the differences mentioned above, the picture concerning the depiction of crime and immigration in the media is approximately the same, focusing on similar themes discussed in the previous section.

\section{Key Research Questions}

As can be noted from the overview of prior research above, the current study will add to the steadily-growing research available in Norway, whilst also venturing to cover the gap left in Phelps et al.'s (2009) study with regard to whether or not there has been an evident shift over time from race to religion as a main marker of difference when the media reports on immigrants and crime. The concepts and accompanying research discussed above have thus informed three research questions, all of which will be addressed in the upcoming sections:

1. Is the primary discourse in the reporting of immigration and violent crime in the Norwegian print media a discourse of threat, and, if so, has it increased over time?

2. Has there been a shift from ethnically-based race words to religiously-based race words over the study period?

3. What types of themes have been used in the construction of threat over the study period?

It should be noted that, in alignment with Blalock's (1967) group threat theory, after World War II, and the subsequent experience of Nazism, there has been a cumulative ideological shift in Western Europe regarding traditional standards of racism (Barker, 1981; Taguieff, 1988; Miles, 1989; \& Rydgren, 2008). New forms of racism are based not on biology and hierarchies, but rather culture and difference, with the main proponents of these views emphasising insurmountable differences between ethnicities and implying that a merging of these identities would only lead to an abolition of the so-called unique qualities constituting these diverse ethnic groups (Brox, 1997; Lien, 1997; Rygren, 2008). Over the past 70 years, various practices of assimilation, multiculturalism and segregation within Western European societies have served to highlight this ideological shift, with proclamations such as German chancellor Angela Merkel's now-notorious 2010 statement that "state multiculturalism is a failure" (Cunningham, 2011, p. 5) serving to exacerbate such toxic sentiments. Prior research, in both Norway and the rest of the Western world, asserts that the media negatively depicts minorities, immigrants and refugees as threatening, and gives a disproportionate amount of coverage to crime involving minorities. However, there is a gap in our understanding of the construction of immigrants and threat; chiefly, whether there been an ideological shift from race to religion as the primary marker of difference in the construction of threat discourse.

\section{Method}

As highlighted above, the purpose of this paper is to explore the construction of criminal threat and immigrants in the content of Norwegian print media coverage of violent crime. This aim will be achieved by conducting a longitudinal content analysis on the crime coverage of the two most prominent Norwegian-language newspapers currently in circulation in Norway, Aftenposten (AP) and Verdens Gang (VG) from the years of 2000 to 2014.

\section{Methodological Approach}

A content analysis of media sources is a valuable way of deciphering possible meaning in two key ways: (1) by focusing on the important key messages in stories; and (2) by focusing on the features of the media that request our attention. There are primarily four approaches to carrying out a content analysis: formal content analysis, thematic analysis, textual analysis, and audience analysis (Pawson \& Tilley, 1997). For the purposes of this study, a formal content analysis, as well as a thematic analysis, will be conducted. As highlighted by Maneri and ter Wal (2005), formal content analysis is often implemented to quantitatively examine several bodies of text and has both lexical indices (units of analyses as linguistic units) and coding categories (units of analyses that correspond to the articles 
or are subsets of them). In contrast, for thematic analysis, the usual strategy is to focus on a particular area of reportage and subject it to a very detailed analysis to identify the underlying processes and intentions of the authors of the communication (Pawson \& Tilley, 1997). This paper will focus on a subset of thematic analysis known as discourse analysis in order to expose possible latent meanings (Maneri \& ter Wal, 2005). In discourse analysis, the news text is implemented as the primary focus for analysis, combining insights from the social constructionist and news-making approaches mentioned in the previous chapter with linguistic and social-cognition analyses. Moreover, this approach is focused on headlines and topics, quotation patterns, argumentation, and narrative (ter Wal, 2002; Maneri \& ter Wal, 2005).

\section{Data Source}

The current study uses data from newspaper stories on violent crime from two Norwegian newspapers from the years 2000 to 2014, obtained from online archives. The newspapers selected are the two most well-read papers in Norway, Aftenposten (AP) and Verdens Gang (VG) (with a respective readership of 412,005 and 380,190 individuals daily (Press Reference, 2015)). These two newspapers are considered a tabloid (VG) and a broadsheet (Aftenposten) respectively. As stated in Chapter 1, although readership figures for print media have decreased in recent years due to the availability of online media resources, Norwegians are still considered to be among the most avid newspaper-consuming populations in Europe, with a sale of 600 copies per 1,000 inhabitants (Norsk Mediabarometer (SSB), 2014; Slaata, 2015). Furthermore, even though the total circulation of newspapers fell 2.8 percent in 2009, the average Norwegian reads 1.8 newspapers per day (The Nordic Page, 2009; Slaata, 2015). More generally, although a common criticism of studies of press discourse is that the impact and audience size of the press are minor when compared with those of television, print media still plays an important role. Newspapers remain a key means of credibility-enhancement in interviews, set the agenda for other media, and can play a crucial role in local mobilisations and the definition of most local issues related to crime and migration (Maneri \& ter Wal, 2005). These factors justify the use of print media as a valid data source independent of other media content, such as the nationally-televised nightly news on $N R K$, the government-funded television station.

\section{Sample}

The sample consists of 180 randomly-selected violent crime stories published between the years of 2000 to 2014 . The time-frame of 2000 to 2014 was selected for two reasons. First, during this period, a new anti-immigrant movement gradually emerged and gained momentum in Norway, as well as in Scandinavia in general, (Eriksen, 2012). As shown in Figure 3.1, between 2000 and 2014, there has been a rapid shift in Norway from a largely homogeneous society to a more heterogeneous, multicultural one (Eriksen, 2012; Lund 2004; Wiggen 2012).

In the current paper, stratified random sampling procedure was used to select the newspaper articles. To do this, the 14-year period was divided into three separate time-periods, spanning approximately five years each:

1. First time-period $-01 / 01 / 2000-31 / 12 / 2004$

2. Second time-period - 01/01/2005-31/12/2009

3. Third time-period $-01 / 01 / 2010-31 / 12 / 2014$

There are several reasons the time periods were divided in this way, as they each revolve around critical dates of significant, race-related events and transitions. In the first time-period, it is anticipated that the rise of neo-Nazi groups in Norway, such as the Boot Boys, will be covered in the media, as in January 2001 (pre-9/11), the racerelated murder of 15-year-old Benjamin Hermansen, a Norwegian boy of mixed Norwegian-African descent at the hands of neo-Nazis, took place. The debate was punctuated a year after the second event, however, in October 2008, when Ali Farah used a post-colonial framework to respond to the massive media coverage of a book written by one of the ambulance drivers, in which he had described how terrible it had been for him to be publicly accused of racism. Farah created an image of white people as a rather cruel global enemy and lost the sympathy of a Norwegian audience characterised more by ideas of colonial innocence than colonial complicity. In the third and final time period, experimental research carried out by Midtbøen and Rogstad (2012) on discrimination in working life concluded that having a foreign name reduces one's chance of being invited to a job interview by $25 \%$ - a finding that has been discussed in many media. Moreover, the last time period seems to be the most active in terms of the topic of racism and discrimination, due to a number of other events that have occurred, such as the mostly over- 
exaggerated Oslo rape crime wave of 2007 to 2012, the increasing political power of a formerly extreme right-wing government party (The Progress Party or Frp for short).

\section{Procedure}

Within each period, 30 violent crime stories per newspaper were randomly selected. The archive databases were sorted from the oldest-to-newest date per time period. In order to identify relevant articles, the online newspaper archives were searched using the following $10 \mathrm{key}$ terms to maximise the identification of violent crime stories (with the Norwegian-language search words italicised): (1) Crime in Norway (kriminalitet i Norge), (2) violence (vold), (3) kill (drap), (4) murder (mord), (5) rape (voldtekt), (6) terrorism (terrorisme), (7) human trafficking (menneskehandel), (8) domestic violence (vold i hjemmet), (9) prison (fengsel), and, finally, (10) prisoner (fanger).

\section{Coding}

The randomly-selected media articles in the sample were then coded, using a schedule relevant to the theoretical concepts and themes from the literature discussed in the previous chapter. It was determined via his research that the discourse of the Progress Party (Frp) includes anti-immigration and anti-immigrant themes, ethno-nationalism (and more specifically, the ethno-pluralist doctrine), and various welfare chauvinist frames, all of which have been important instruments for mobilising voter support in Norway. The race-based words recorded were words that have typically been found in similar studies involving newspaper data sets (for example, Phelps et al., 2011), as well as a few race-based words that either appeared to be typical of this sample. The term "Islamisation by stealth" has also been used by participants on online debate forums of the tabloid $V G$ in particular as early as 2003 and was claimed by the Progress Party (Frp) in 2006, when Siv Jensen, the party's leader, initially and infamously employed the term in a speech admonishing immigration (Strommen, 2011, p. 191).

\section{Reliability of Coding}

Reducing potential threats to the reliability of the coding scheme was also important. Reliability alludes to the consistency and replicability of the analysis and is reliant on whether other researchers would have coded the information in a similar manner (Weber, 1990). Inconsistent results can occur due to numerous factors, including ambiguous coding rules, basic errors in the recording of data, or cognitive variances between coders (Weber, 1990). As a single coder (the researcher) was involved, the current study is dependent upon the 'stability' of the coding scheme as a measure of its reliability. Stability "refers to the extent to which the results of the content classification are invariant over time (and occurs when) the same content is coded more than once by the same coder" (Weber, 1990 , p. 17). To check the inter-coder reliability, $10 \%$ of the articles in the randomly-selected sample were recoded 3 months after the original coding occurred, with the results displaying a $90 \%$ recoding accuracy. At each session, data was coded and recorded, according to the coding schedule. The coding between each reading was then compared, and any inconsistencies resolved.

\section{Analytic Technique}

The analysis was performed in two stages. First, a quantitative analysis exploring any significant changes over time was conducted using cross-tabulations and chi-square tests of independence, which were calculated using SPSS, Version 22 (IBM, 2013). Cross-tabulations are a useful statistical tool that allows one to compare the relationship between two or more variables. Pearson's chi-squared test of independence is a statistical test applied to sets of categorical data to evaluate how likely it is that any observed difference between groups arose by chance. As one of the main aims of this study is to observe whether there has been a change in immigrant and crime discourse over these three time-periods, conducting chi-squared tests is also appropriate for this purpose. As the sample size of this study is rather small, due to the time constraints of the research (as it was conducted as part of a thesis), 0.10 will be accepted as a level approaching significance, although 0.05 is what is conventionally used. The use of 0.10 as the threshold has been the practice in similar, smaller-sized studies (Gigerenzer et al., 2004). A significance level of 0.10 simply indicates that there is a $10 \%$ probability that the results are due to chance. Furthermore, probabilities greater than 0.10 are rarely used, as such a practice is considered risky regarding the statistical significance of a data set (Gigerenzer et al., 2004). The second stage of the analysis, which aimed to address the third research question, examined in more depth the construction of threat within our data set through a qualitative thematic analysis of a random sub-sample of the original crime articles that were identified as containing a threat discourse. This was conducted to better understand the way in which threat concerning immigrants and crime has been constructed in the Norwegian media, as well as to give extra weight or added dimension to the results procured in the quantitative analysis in stage one. 


\section{Results:-}

As discussed in the method section, to discern the presence and nature of threat discourses over time in Norwegian print media, a mixed method approach was adopted, relying on a randomly-selected sample of 180 Norwegianlanguage newspaper articles. These newspaper articles were collected from the two most widely-read newspapers in Norway (Verdens Gang (VG) and Aftenposten (AP)) between the years of 2000 to 2014. This chapter presents the results of the quantitative content analysis, as well as the thematic qualitative analysis. The quantitative content analysis answers the first two key research questions in this study, namely:

1. Is the primary discourse in the reporting of immigration and violent crime in the Norwegian print media a discourse of threat, and, if so, has it increased over time?

2. Has there been a shift from ethnically-based race words to religiously-based race words over the study period?

Furthermore, the third research question — what types of themes have been used in the construction of threat over the study period? —is addressed in the qualitative thematic analysis.

\section{Quantitative Results \\ Presence and nature of threat discourse}

As noted above, the quantitative analysis examines whether there is a threat discourse around crime and immigration, as well as whether it has changed over the study period. In order to achieve these aims, the analysis focuses on the types of violent crime reports in Norwegian newspapers during the time period mentioned above, the type of discourses used in these reports, and the number of ethnic and religiously-based words used. In addition, the analysis will also look at the type of sources and political party quoted in the articles. The relationships between these variables will be examined by newspaper type (i.e., tabloid vs. broadsheet), and time-period. Type of sources quoted will also be examined. Moreover, as stated in Chapter 3, the race-based words recorded were words that have typically been found in similar studies involving newspaper data sets (for example, Phelps et al., 2011), as well as a few race-based words that either appeared to be typical of this sample (ethnic Norwegian and snikislamisering (translated as Islamisation by stealth)) or were recorded for the purpose of detecting whether or not a shift from race to religion was present. As such, the quantitative analysis of the findings is divided into six sections below:

1. Type of crime reported

2. Type of discourse

3. Type of race words

4. Experts/Sources quoted (including political party)

5. News source/Type of paper

\section{Type of crime reported}

Table 4.1 below shows the distribution of crime types in the sample for the study period. To assist in readability, the 10 crime keywords were recoded into non-violent and violent (coded as $0=$ non-violent, $1=$ violent). 
Table 4.1: Distribution of Type of Crime Reported by Time Period

\begin{tabular}{|c|c|c|c|c|}
\hline Type of crime & $\begin{array}{c}\text { Time period } 1 \\
(2000-2004) \\
\text { n }(\%)\end{array}$ & $\begin{array}{c}\text { Time period } 2 \\
(2005-2009) \\
\text { n (\%) }\end{array}$ & $\begin{array}{c}\text { Time period } 3 \\
(2010-2014) \\
\text { n }(\%)\end{array}$ & $\begin{array}{l}\text { Total } \\
\text { n (\%) }\end{array}$ \\
\hline Non-violent & $\begin{array}{c}20 \\
(11.1 \%)\end{array}$ & $\begin{array}{c}18 \\
(10 \%)\end{array}$ & $\begin{array}{c}18 \\
(10 \%)\end{array}$ & $\begin{array}{c}56 \\
(31.1 \%)\end{array}$ \\
\hline Violent & $\begin{array}{c}40 \\
(22.3 \%)\end{array}$ & $\begin{array}{c}42 \\
(23.3 \%)\end{array}$ & $\begin{array}{c}42 \\
(23.3 \%)\end{array}$ & $\begin{array}{c}124 \\
(68.9 \%)\end{array}$ \\
\hline Total & $\begin{array}{c}60 \\
(33.3 \%)\end{array}$ & $\begin{array}{c}60 \\
(33.3 \%)\end{array}$ & $\begin{array}{c}60 \\
(33.3 \%)\end{array}$ & $\begin{array}{c}180 \\
(100.0 \%)\end{array}$ \\
\hline
\end{tabular}

NOTE: $X^{2}$ (D.F.) $=1.21(4), p<0.10$ (Terrorism and violent crime have been included as one result in this table. If disaggregating the results of violent crime and terrorism, there is evidence suggestive of more reporting of violent crime since 2005).

As shown in the Table 4.1, overall a total of 124 (or 68.9\%) violent crimes, and 56 (or 53.8\%) non-violent crimes were reported over the entire study period, which supports arguments that violent crime tends to get more coverage than non-violent crime (Maneri \& ter Wal, 2005; Walgrave and van Aelst, 2006; DeKeseredy and Dragiewicz, 2012).

\section{Type of Discourse}

Table 4.2 below summarises the presence of a threat discourse in each time period. Recall that threat discourse was coded according to the use of negative emotive content present in the news stories in the data set. As is evident from the table, the use of threat discourse peaked (at 46 cases or 37.4\%) in time-period 2 (2005-2009). The relationship between the presence of threat discourse and each time-period was statistically significant at $\mathrm{p}<0.10 \mathrm{X} 2(\mathrm{D} . \mathrm{F}$.) $=$ $4.78(2), \mathrm{p}<0.10$

Table 4.2: Relationship of Threat Discourse by Time Period

\begin{tabular}{ccccc}
\hline & Time Period 1 & Time Period 2 & Time Period 3 & Total \\
& $(2000-2004)$ & $(2005-2009)$ & $(2010-2014)$ & $\mathrm{n}(\%)$ \\
& $\mathrm{n}(\%)$ & $\mathrm{n}(\%)$ & $\mathrm{n}(\%)$ & 123 \\
Threat Discourse & 42 & 46 & 35 & $(100.0 \%)$ \\
$\mathrm{n}(\%)$ & $(34.1 \%)$ & $(37.4 \%)$ & $(28.5 \%)$ & 57 \\
Non-Threat & 18 & 14 & 25 & $(100.0 \%)$ \\
Discourse n (\%) & $(31.6 \%)$ & $(24.6 \%)$ & $(43.9 \%)$ & 180 \\
Total & 60 & 60 & 60 & $(100.0 \%)$ \\
$\mathrm{n}(\%)$ & $(33.3 \%)$ & $(33.3 \%)$ & $(33.3 \%)$ &
\end{tabular}

NOTE: $X^{2}$ (D.F.) $=4.78(2), p<0.10$

Type of Race Words

Although threat discourse may not have varied by type of crime reported over the three time-periods (2000 to 2004, 2005 to 2009, 2010 to 2014), whether or not the type of discourse was related to the use of ethnic or religious words (none, ethnic, religious or political) was also examined. The relationship between the use of race-based words and 
each time-period was significant $(\mathrm{X} 2$ (d.f.) $=10.21(3), \mathrm{p}<0.05)$. Furthermore, the table suggests that religiousbased words have increased proportionately in the reporting of crime; but there has not necessarily been a reduction in the use of ethnic-based words. Although there was fewer articles used ethnic based words in time-period 2 (2005 to 2009), their use had increased in time-period 3 (2010 to 2014).

\section{Experts/Sources Quoted}

Across the full sample, politicians were the most-quoted source $(51.7 \%$ of the articles coded quoted a political figure, or 93 of the 180 articles in the data set). This is supportive of a political agenda-setting role of the media, in accordance with the principles of McComb's and Shaw's (1972) agenda-setting hypothesis, as well as Walgrave and van Aelst's (2006) assertion that the political agenda interacts with media agendas to affect policy change, previously expanded upon in the background and method sections

\section{Type of News Source/Type of Paper}

An important issue was to distinguish whether the use of threat discourse differed between the two different types of newspaper sources used in this study. As stated previously, the data comes from Norway's two most widely-read newspapers, Aftenposten (AP) and Verdens Gang (VG). Aftenposten (AP) is generally classified as a "broadsheet"style newspaper, whereas Verdens Gang (VG) tends to be classified as a "tabloid"-style newspaper. In comparison to more serious "broadsheet"-type news, tabloid journalism tends to emphasise topics that are sensational in nature, such as crime, celebrity gossip, or hot-button issues, such as immigration (Grebe et al., 2000).

A significant relationship was found between race words, threat discourse, and type of news source (X2 (def.) 10.21(3), $\mathrm{p}<0.05$ ). In contrast, there was no appreciable difference in the amount of religiously-based race words used within a threat discourse article in the tabloid-style newspaper, as opposed to the broadsheet-style paper, equalling $41.9 \%$ and $43.9 \%$ consecutively (with the higher percentage surprisingly belonging to the "broadsheet"style newspaper).

\section{Qualitative Results}

The quantitative analysis suggests that the nature and type of threat discourse has changed over the study period, particularly during 2005 to 2009 (time-period 2), and that there was a significant relationship between religiouslybased race words, threat discourse and time-period ( $\mathrm{p}<0.001)$. However, the current study had an atypically small sample size for a longitudinal analysis. Hence, certain results failed to yield an appreciable difference between variables, such as those between type of political party, crime and time-period ( $p>0.10)$. In order to remedy this shortcoming, and also to gain a more thorough understanding of how this discourse presented itself, a qualitative thematic analysis was conducted to explore the types of themes used in the construction of threat over the selected study period. In order to achieve this, a sub-sample ( $\mathrm{n}=19$, or one-third) of the 57 articles that had been identified as containing threat discourse were randomly selected. Overall, two main themes were identified in the language used in the construction of threat discourse in the sub-sample of the crime articles analysed. These were:

Emotive and discriminatory language used in association with immigrants, some of which reveal an ignorance or intolerance toward those deemed as having a dissimilar culture to that of Norwegians and aimed primarily at either Muslim immigrants or those labelled as having a "non-Western background."

Common examples in my data sample included:

"In the Muslim-majority suburb of Groruddalen in Oslo's East, immigrant boys are angrier than Norwegian boys, and display a lack of self-restraint that could potentially lead to violence" (VG, 13.05.11, p. 4).

"If the 'white-flight' of people from Groruddalen in East Oslo continues, Groruddalen will undoubtedly, along with the rest of East Oslo, transform into a ghetto within the next 20-30 years" (Aftenposten, 15.04.11, p. 2).

The issues that the above quotes capture are all examples of a threat discourse present in Norwegian media, based on discrimination, as they demonstrate a fear of the majority being overtaken and replaced by a minority "other." Moreover, emotive and discriminatory language appeared as a consistent theme in both Aftenposten (broadsheet) and $V G$ (tabloid) papers but appeared more evenly distributed across time periods for Verdens Gang (VG), when compared to Aftenposten (Ap), where it was more clustered in time period three. This theme has been found in 
previous studies (e.g., Nafstad et al., 2009; Phelps et al., 2011; Wiggen, 2012; Bye et al., 2014) on similar subjects in Norway regarding discrimination and Muslims, and the current paper is no exception to this observation.

\section{Terror, criminality, and uncertainty regarding immigrants and immigration}

Issues concerning terror, immigrant criminality, and uncertainty can be implemented by the media to construct an agenda, which also increases the prospective group threat and fear (Lithman, 2004; Maneri \& ter Wal, 2005; Walgrave \& van Aelst, 2006; Nafstad et al., 2009; Phelps et al., 2011; Eriksen, 2012; Wiggen, 2012; Esses et al., 2013; Bangstad, 2015). This was also found in the sub-sample, with examples of an overt linking of threat to particular groups common in the language employed, especially with reference to 'non-Western' immigrants. Some examples of this across each time-period are highlighted below:

"Immigrants are more criminal than ethnic Norwegians" (VG, 24.03.03, p. 2).

"Not all Muslims are terrorists, but all terrorists are Muslims" (Carl I. Hagen, former leader of Frp, VG, 17.08.11, p. 2).

Furthermore, violent crime tended to be tied with immigrants (especially those of "non-Western origin") within the sub-sample. A significant example of this type of discourse can be seen in the report of the so-called 'rape epidemic' between the years of 2007 to 2012 :

"Nine out of ten rape reports filed by women contain descriptions of men that are predominantly African and/or Middle Eastern in origin; ethnic Norwegian women are dyeing their normally blonde hair black for fear of being attacked if and when they may find themselves on the streets alone at night" (Police Commissioner, VG, 08.02.11, p. 2).

\section{Summary:-}

The current section presented both the quantitative and qualitative results of the data set of the current study, first by conducting a content analysis, and then a thematic analysis. Furthermore, by analysing the available data, the three research questions stated at the outset of this chapter were addressed.

The first two questions were answered via the content analysis, which found that the nature and type of threat discourse changed over the study period, particularly during 2005 to 2009 (time period 2), and that there was a significant relationship between religiously-based race words, threat discourse and time period (X2 (def.) $=18.86$ $(6), p<0.001)$. When cross-tabulations of race words, in conjunction with both threat discourse and time period were conducted, the figures reached a level of significance $(X 2$ (def.) $=10.21(3), p<0.05)$. However, the current study had an atypically small sample size for a longitudinal analysis. Hence, certain results failed to yield an appreciable difference between variables, such as those between type of political party, crime and time period (X2 (def.) $=10(8.1), \mathrm{p}>0.10)$. The thematic qualitative analysis, on the other hand, answered the third research question by addressing the themes which had been implemented to construct discourses of threat over the selected time period, with two themes, that of emotive and discriminatory language, and that of terror, immigrant criminality and uncertainty emerging as the main semantic dialogues in the Norwegian media.

\section{Discussion and Conclusion:-}

The media plays an important role in influencing public perceptions and policy on crime and justice (Lithman, 2004; Maneri \& ter Wal, 2005; Walgrave \& van Aelst, 2006). Research has shown that media accounts that link threat of crime to particular populations, such as immigrants, can shape anti-immigrant attitudes within communities (Chiricos \& Eschholz, 2002; Wiggen, 2012; Esses et al., 2013). However, to date, much of this research has been conducted in English-speaking countries. In times of increasing immigration all around the world, as well as growing global concerns around terrorism, Norway provides an interesting case study, as it has been a relatively homogenous society which has only recently experienced a drastic increase in its immigrant population numbers (Eriksen, 2012). Although the political climate in Norway is similar to the rest of Europe, who are also currently experiencing high racial tensions due to mass immigration, Norway is unique due to its implicit characteristics of egalitarianism and tolerance, as well as its presumed colonial innocence (Gullestad, 2002; Lithman, 2004). Furthermore, Norway is a country that is highly nationalistic, and, somewhat because of this, is one of the few remaining countries in Europe that is not a member of the European Union and continues to treat the European Union with a mixture of disinterest and scepticism (Sundlisæter-Skinner, 2012). 


\section{Summary of Findings}

This study, in answering the three research questions outlined above, uncovered three main findings of interest. To begin with, the first two questions were answered via the content analysis, which found that the nature and type of threat discourse changed over the study period, particularly during 2005 to 2009 (time period 2), and that there was a significant relationship between religiously-based race words, threat discourse and time period (X2 (d.f.) $=18.86$ $(6), p<0.001)$. When cross-tabulations of race words, in conjunction with both threat discourse and time-period were conducted, the figures reached a level of significance (X2 (D.F.) = 10.21 (3), p < 0.05). However, the current study had an atypically small sample size for a longitudinal analysis. Hence, certain results failed to yield an appreciable difference between variables, such as those between type of political party, crime and time period (X2 $(D . F)=.10(8.1), p>0.10)$. Interestingly, the most frequently-occurring experts used in the articles were politicians (51.7\% of the articles, with the most frequently-quoted party being the Progress Party (Frp), at 25\%). Secondly, the increase in a discourse of threat was particularly notable when religiously-based words (i.e., Muslim, 'Islamisation by stealth' ('snikislamisering' in Norwegian)) were included in the analysis. Throughout all three time-periods, the study suggests that there was a shift from ethnically-based race words to religiously-based race words associated with threat, thus answering in the affirmative regarding the second research question $(\mathrm{X} 2(\mathrm{~d} . \mathrm{f})=.18.86(6)$, $\mathrm{p}<$ $0.001)$.

\section{Implications}

When compared with other research on media accounts of immigrants and crime, outlined in the literature review section of this paper, the current study found similar results: despite the image of Norwegian tolerance, there was an identifiable discourse of threat, linking immigrants, and increasingly, Muslims, to crime and violence in the two main Norwegian newspapers. A key reason for the increasing anti-immigrant discourse in Norwegian papers may be found in the impact of globalisation. In fact, between the years of 1970 and 2005, the total international migration stock increased from around 80 million people, to over 190 million (Lucas, 2008). According to several researchers on the subject, such as Franko-Aas (2007), Bosworth et al. (2008), Kaya \& Karakoc (2012), and Berg \& Gleditsch (2014), there are two distinct examples of transnationalisation. The first refers to immigrants who form diaspora communities, thus being perceived by residents of the community as failing to fully integrate into their adopted country's customs and habits. The second form occurs via the processes of globalisation, where certain alliances between certain countries are strengthened based on their intertwining identities, experiences, cultures, habits, and historical roots. Furthermore, the widespread use of the Internet and the advent of social media have ensured that mutual ideas can be shared, expanded upon and spread at an alarmingly rapid pace, sometimes to the point of 'going viral' (Shulman \& Xenos, 2009).

\section{Limitations}

There are several limitations concerning the current study. First, the sample size of the current study (only 180 newspaper articles) impacts the ability to detect significant differences in the data. Due to time constraints (as this study was conducted as part of a thesis), a larger sample was beyond the scope of the current paper, meaning that it is difficult to draw solid conclusions from the results of this study. Although limited, the results do suggest that there is evidence to support a significant relationship between threat discourse, especially religiously-based race words, and particularly in time-period 2. Furthermore, quotes from the randomly-selected $(n=19)$ sub-sample used in the qualitative analysis further support a relationship between these variables, as well as the way in which these issues have been framed by the media over time, setting the agenda. Second, only two newspapers were included in the study. Norway has other, albeit less widely-read, newspapers such as Klassekampen, and online-only based newspapers, such as Nettavisen, which, had they been included, may have given a broader overall perspective on media portrayals of immigrants. $V G$ and Aftenposten (AP) were chosen as they are the two most widely-read newspapers in Norway, and, as such, probably best reflect the majority's opinion regarding crime and immigration. Third, the only media source analysed in this paper was print media. A broader range of media mediums was beyond the scope of the current study, due to it being conducted as part of a thesis, and thus, was subject to both time constraints and word limits.

\section{Future Directions}

Future research should focus on primarily four aspects, including:

1. Broadening the type of media used in research analyses to include other forms, such as TV and online social media. 
2. Exploring the impact of the current European refugee crisis that has evolved and escalated over the past few years since this analysis was conducted, as well as reporting on the recent Brussels, Paris and Nice terror attacks.

3. Expanding the scope of the analysis to include other Western nations for comparison and contrast to Norway's situation.

4. Examining whether there are any theoretical issues from group threat theory or agenda-setting hypothesis that could be further examined and included in future analyses.

\section{Conclusion:-}

International migration is unlikely to recede anytime soon, making it important to understand its impact on media and policy discourse, and how these can influence the public's attitudes toward immigrants and set specific agendas. Prior research has set a strong foundation by examining individual-level characteristics, inter-group dynamics, and group threat processes (Ceobanu \& Escandell, 2010; Fussell, 2014). The current study has added to this research by focusing on the portrayal of immigration, threat, and crime in the Norwegian print media. Furthermore, the media play a central role in portraying Muslims in these societies and are informed in specific ways by the previouslymentioned agendas of power, both at the level of the messages they carry, as well as in their professional practices and structures (Morey \& Yaqin, 2011). As Islam is increasingly constructed as standing in opposition to secular modernity, so have Muslim immigrants been judged as having failed national 'integration' tests, particularly in Europe, where once-homogeneous nations now struggle to cope with their increasing diversity, responding with fear and uncertainty in the vein of the principles outlined by Blalock's (1967) group threat theory (Crawford, 2006). Finally, the public debate on immigration revolves around the negative effects of immigration - as is evident in the quotes from the thematic qualitative analysis section of this paper - which hint at a dilution of the domestic or origin culture, instead of on its potentially positive effects. Therefore, further research on this topic is required to responsibly monitor the progress of threat discourses through all mediated mediums, and also to inform when there are clear cases of misinformation.

Funding: No funding was provided as part of this research.

\section{Acknowledgments:-}

This paper would not have been possible without the ongoing guidance of my supervisor, Dr Christine Bond, from the School of Criminology and Criminal Justice, Griffith University, Brisbane, Queensland, Australia. I would also like to thank my husband, Frode, and my two sons, Glen and Heath, for their ongoing support, love, and encouragement they have shown whilst I have been engaged in my studies and helping me to realise my dreams.

Conflict of Interest: I declare no conflict of interest 


\section{References:-}

1. Altheide, D.L. (2002). Creating Fear: News and the Construction of Crisis. New York: Walter de Gruyter.

2. Bakken, A. (1998). Youth in the Big City. Oslo: NOVA Rapport.

3. Bangstad, S. (2015). The racism that dares not speak its name: Rethinking Neo-nationalism and Neo-racism. Intersections, 1 (1), 49-65.

4. Barker, M. (1981). The New Racism. London: Junction Books.

5. Barkin, S. (2003). American Television News: The Media Marketplace and the Public Interest. Armonk, NY: ME Sharpe.

6. Berg, J.A., \& Gleditsch, R.F. (2014). Norwegians' attitudes toward immigrants and immigration policy: Symbolic politics and group threat. International Journal of Sociology, 2, 124-131.

7. Blalock, H.M. (1967). Toward a theory of minority-group relations. New York: Capricorn Books.

8. Bobo, L. (1988). Group conflict, prejudice, and the paradox of contemporary racial attitudes. In Eliminating Racism (pp. 85-114). United States: Springer US.

9. Bosworth, M., Bowling, B., \& Lee, M. (2008). Globalization, ethnicity and racism: An introduction. Theoretical Criminology, 12 (3), 263-273.

10. Breed, W. (1955). Social control in the newsroom: A functional analysis. Social Forces, 33 (4), 326-335.

11. Brox, O. (1997). Intergration, underclass and marginalisation - Some reflections on the current immigration crisis. Samfunnsforskning, 38 (2), $252-255$.

12. Bye, H.H., Herrebrøden, H., Hjetland, G.J., Røyset, G.Ø., \& Westby, L.L. (2014). Stereotypes of Norwegian social groups. Scandinavian Journal of Psychology, 55, 469-476.

13. Ceobanu, A.M., \& Escandell, X. (2010). Comparative analyses of public attitudes toward immigrants and immigration using multinational survey data: A review of theories and research. Annual Review of Sociology, $36,309-328$.

14. Chamlin, M.B. (2009). Threat to whom? Conflict, consensus, and social control. Deviant Behaviour, 30 (6), 539-559.

15. Chavez, L.R. (2001). Covering Immigration: Popular Images and the Politics of the Nation. Los Angeles, CA: University of California Press.

16. Chiricos, T., \& Eschholz, S. (2002). The racial and ethnic typification of crime and the criminal typification of race and ethnicity in local television news. Journal of Research in Crime and Delinquency, 39 (4), 400-420.

17. Cohen, B. (1963). The Press and Foreign Policy. Princeton, N.J.: Princeton University Press.

18. Crawford, A. (2006). Networked governance and the post-regulatory state? Steering, rowing and anchoring the provision of policing and security. Theoretical Criminology, 1 (4), $449-480$.

19. Cummins, W.M, \& Gordon, G.G. (2006). Programming our Lives: Television and American Identity. Westport, Conn.: Praeger.

20. Cunningham, F. (2011). The virtues of urban citizenship. City, Culture and Society, 2 (1), 33-44.

21. DeKeseredy, W.S., \& Dragiewicz, M. (2012). Racial/Ethnic variations in violence against women: Urban, suburban, and rural differences. International Journal of Rural Criminology, 1 (2), 184 - 202.

22. Entman, R.M. (1990). Democracy without Citizens: Media and the Decay of American Politics. Oxford: Oxford University Press.

23. Eriksen, T.H. (2012). Xenophobic exclusion and the New Right in Norway. Journal of Community and Applied Sciences, 22 (3), 206-209.

24. Eriksen, T.H. (2013). Immigration and National Identity in Norway. Migration Policy Institute (MPI): Transatlantic Council on Migration.

25. Esses, V.M., Medianu, S., \& Lawson, A.S. (2013). Uncertainty, threat, and the role of the media in promoting the dehumanization of immigrants and refugees. Journal of Social Issues, 69 (3), 518-536.

26. Fleras, A., \& Kunz, J. (2001). Media and Minorities: Representing Diversity in a Multicultural Canada. Toronto: Thompson Educational Publishing, Inc.

27. Fredrickson, G.M. (2002). Racism: A Short History. Princeton, N.J.: Princeton University Press.

28. Franko-Aas, K. (2007). Analysing a world in motion: Global flows meet 'criminology of the other.' Theoretical Criminology, 11 (2), 283-303.

29. Fussell, E. (2014). Warmth of the welcome: Attitudes toward immigrants and immigration policy. Annual Review of Sociology, 40, $479-498$.

30. Gigerenzer, G., Krauss, S., \& Vitouch, O. (2004). The null ritual: What you always wanted to know about significance testing but were afraid to ask. In Kaplan, D. (Ed.). The Sage Handbook of Quantitative Methodology for the Social Sciences (pp. 391 - 408). Thousand Oaks, CA: Sage. 
31. Gorman, L., \& McLean, D. (2003). Media and Society in the Twentieth Century: A Historical Introduction. Oxford: Blackwell Publishing.

32. Greenburg, B.S., \& Mazingo, S.L. (1976). Racial issues in mass media institutions. In Towards the Elimination of Racism (pp. 309-340). New York: Pergamon Press.

33. Gullestad, M. (2002). Blind slaves to our prejudices: Debating 'culture' and 'race' in Norway. Ethnos, 69 (2), 177-203.

34. Henry, P.J., \& Sears, D.O. (2002). The symbolic racism 2000 scale. Political Psychology, 23 (2) 253-283.

35. Hjerm, M. (2007). Do numbers really count? Group threat theory revisited. Journal of Ethnic and Migration Studies, 33 (8), 1253-1275.

36. Hogg, R. (2007). Criminology, crime and politics before and after 9/11. The Australian and New Zealand Journal of Criminology, 40 (1), 83-105.

37. Hudson, B. (2008). Difference, diversity and criminology: The cosmopolitan vision. Theoretical Criminology, $12(3), 275-292$.

38. Hudson, B., \& Bramhall, G. (2005). Assessing the 'Other': Constructions of 'Asianness' in risk assessments by probation officers. British Journal of Criminology, 45 (5), 721-740.

39. IBM. (2013). SPSS Statistics, Version 22.0. New York: IBM Corporation.

40. Jewkes, Y. (2004). The Media and Crime. London: Sage.

41. Jewkes, Y. (2011). The Construction of Crime News. Los Angeles: Sage.

42. Kaya, Y., \& Karakoc, E. (2012). Civilizing vs. destructive globalization? A multi-level analysis of antiimmigrant prejudice. International Journal of Comparative Sociology, 53 (1), 23-44.

43. Kerbel, M.R. (1999). Remote and controlled: Media politics in a cynical age (2nd Ed.). Boulder, CO: Westview.

44. Kinder, D.R., \& Sanders, L.M. (1996). Divided by Color: Racial Politics and Democratic Ideals. Chicago: University of Chicago Press.

45. Kymlicka, W. (2012). Multiculturalism: Success, Failure, and the Future. Migration Policy Institute Europe (MPIE): Transatlantic Council on Migration.

46. Ladegaard, H.J. (2013). Beyond the research of ethics and equity? Depersonalisation and dehumanisation in foreign domestic helper narratives. Language and Intercultural Communication, 13 (1), 44-59.

47. Lien, I.L. (1997). How do we diagnose racism? A problem for both immigrants and researchers (De liker oss ikke: Den norske rasismens ytringsformer). Oslo: Tano Aschehoug.

48. Lippmann, W. (1922). Public Opinion. Oregon: The University of Oregon Press.

49. Lithman, Y. (2004). When researchers disagree: Epistemology, multiculturalism, universities and the State. Ethnicities, 4 (2), 155-184.

50. Lucas, S.R. (2008). Constructing Colour-blind Classrooms - Everyday Racism; Getting Real about Race in School. New York: Sage.

51. Lund, M. (2004). Sweden's Equal Law. Stockholm: Kalla Kullor Forlag.

52. Maneri, M., \& ter Wal, J. (2005). The criminalisation of ethnic groups: An issue for media analysis. Forum of Qualitative Social Research, 6 (3), 1-21.

53. Markert, J. (2010). The changing face of racial discrimination: Hispanics as the dominant minority in the USA A new application of power-threat theory. Critical Sociology, 36 (2), 307-327.

54. McCombs, M.E., \& Shaw, D.L. (1972). The agenda-setting function of the mass media. Public Opinion Quarterly, 36, 176-187.

55. Meertens, R.W., \& Pettigrew, T.F. (1997). Is subtle prejudice really prejudice? Public Opinion Quarterly, 61 (1), 54-71.

56. Midtbøen, A.H., \& Rogstad, J. (2012). Discrimination: Methodological controversies and socological perspectives on future research. Nordic Journal of Migration Research, 2 (3), 203-212.

57. Miles, R. (1989). Racism: Key Ideas. London and New York: Routledge.

58. Morey, P., \& Yaqin, A. (2011). Framing Muslims: Stereotyping and Representation after 9/11. MA: Harvard University Press.

59. Nafstad, H.E., Blakar, R.M., Carlquist, E., Phelps, J.M., \& Rand-Hendriksen, K. (2009). Globalisation, Neoliberalism, and community psychology. Journal of Community Psychology, 43, 162-175.

60. Norsk Mediabarometer (SSB). (2014). Newspaper Sales Figures, 2014. Oslo: Statistisk Sentralbyrå (Statistics Norway).

61. Pawson, R., \& Tilley, N. (1997). Realistic Evaluation. London: Sage. 
62. Phelps, J., Ellertsen, D.E., Turken, S., \& Ommundsen, R. (2011). Integrating immigrant minorities: Developing a scale to measure majority members' attitudes toward their own proactive efforts. Scandinavian Journal of Psychology, 52 (4), 404-410.

63. Press Reference. (2015). Most-read newspapers in Norway, 2015. www.pressreference.com. Retrieved 28th October, 2015.

64. Quillian, L. (1995). Prejudice as a response to perceived group threat: Population composition and antiimmigrant racial prejudice in Europe. American Sociological Review, 60 (4), 586-611.

65. Rydgren, J. (2008). Immigration sceptics, xenophobes or racists? Radical right-wing voting in six West European countries. European Journal of Political Research, 47, 737-765.

66. Rogers, E.M., \& Dearing, J.W. (1988). Agenda-setting research: Where has it been, where is it going? Communication Yearbook, 11, 555-594.

67. Shulman, S., \& Xenos, N. (2009). Challenging the civic/ethnic and West/East dichotomies in the study of nationalism. Comparative Political Studies, 35 (5), 554 - 585.

68. Slaata, T. (2015). Print versus digital in Norwegian newspapers. Media, Culture, \& Society, 37 (1), $124-133$.

69. Sundlisæter-Skinner, M. (2012). Norwegian Euroskepticism: Values, identity, or interest. Journal of Common Market Studies, 50 (3), 422 - 440.

70. Taguieff, P.A. (1988). The Strength of Prejudice: Racism on Trial. Paris: La Decouverte.

71. ter Wal, J. (2002). Racism and Cultural Diversity in the Mass Media. An Overview of Research and Examples of Good Practice in the EU Member States, 1995-2000. Vienna: European Monitoring Centre on Racism and Xenophobia.

72. The Nordic Page. (2009). How many newspapers do Norwegians read a day? www.tnp.no. Retrieved 11th March, 2015.

73. Thomas, W.I., \& Thomas, D.S. (1928). The Child in America: Behaviour Problems and Programs. New York: Knopf.

74. Walgrave, S., \& van Aelst, P. (2006). The contingency of the mass media's political agenda-setting power: Toward a preliminary theory. Journal of Communications, 56, 88-109.

75. Weber, R.P. (1990). Basic Content Analysis (No. 49). London: Sage.

76. Weimann, G. (2000). Communicating Unreality: Modern Media and the Reconstruction of Reality. London, UK: Sage.

77. Wiggen, M. (2012). Rethinking anti-immigration rhetoric after the Oslo and Utøya terror attacks. New Political Science, 34 (4), 585-604.

78. Wilson, C.C. (2002). The paradox of African-American journalists. In Ethnic Minorities and the Media (pp. 8599). Buckingham: Open University Press. 